\title{
AN IOT AND BLOCKCHAIN APPROACH FOR THE SMART WATER MANAGEMENT SYSTEM IN AGRICULTURE
}

\author{
YUNYAN CHANG* JIAN XU; AND KAYHAN ZRAR GHAFOOR ${ }^{\ddagger}$
}

\begin{abstract}
In all the smart applications, evolution of the Internet of Things (IOT) is utilized as a complete matured technology and in the future internet generations, established itself. Block-chain is also the blooming technique like Internet of things in which the distributed ledger which enhances the security contained in the each node of the block-chain. In the block-chain network, any fault transaction is not done by the illegal users. The block-chain is combined with the Internet of Things for the improvement of real time application performance. IOT based smart water management system is designed in this paper for the agriculture which ensures the effectiveness of the agriculture water management. The remote monitoring with the IOT is used for this purpose. By linking with 2D modelling, the control and management of the agriculture water were performed. Finally, a system is implemented for the agriculture water management through the real time data collection. The obtained result shows the data that updates the water monitoring interface with the varying number of hours. The IoT technology and remote monitoring technology is utilized to the existing water management infrastructure. For water resources management and water supply, this is the very efficient technology.
\end{abstract}

Key words: Internet of Things, Block-chain technology, 2D modelling, Fault transaction, water management system

AMS subject classifications. 68M11

1. Introduction. The use of water resources and quality of service is optimized by the smart water management in supply systems. The integration of multiple technologies, storing and analyzing data from different sources in real-time is enabled by the Internet of Things (IoT). All operational scenarios in IoTbased systems can be difficult to anticipate and to establish how managers should act in each situation. The operational processes through conventional workflows are modelled which are based on the fixed flows. To deal with water systems, the flexibility provided by declarative processes can be an adequate solution. The execution of every activity is allowed by the declarative paradigm and it ensures that the policies of management will be executed.

The implementation of the monitoring framework is illustrated in the Fig 1.1. First of all, in the water supply system, installations of sensors are done for data collection. Then CEP technology is used for the data execution for recurring patterns of water loss identification. On occurrence of water loss, alarms are triggered. The one or more tasks are executing the water management agents. In the control panel, enabling and disabling of tasks is done by a declarative business process.

In the agricultural activities, the agricultural water is a vital element however due to changes in conditions like an increase in the cost of water management for supply and deepening of climate change phenomenon, a lot of inconveniences is experienced by the farmers. For agricultural water use and management, management of water demand has been increased.

IOT infrastructure is focussed to demonstrate and evaluation of the some implementation possibilities. The sensors generate the copious amounts of data which are analyzed by the innovative strategies addressed by other works. Patterns like water leakages are identified by the big data technologies and the adequate response time in the context of water systems is not presented. The analysis must produce the required results in real time

\footnotetext{
*School of Computer and Software, Weifang University of Science and Technology, Weifang, Shandong, 262700, China (Yunyanchang112@outlook.com).

†School of Computer and Software, Weifang University of Science and Technology, Weifang, Shandong, 262700, China (Jianxu111@gmail.com).

${ }^{\ddagger}$ Department of Computer Science, Knowledge University, Erbil 44001, Iraq (kayhan.zrar@knu.edu.iq).
} 


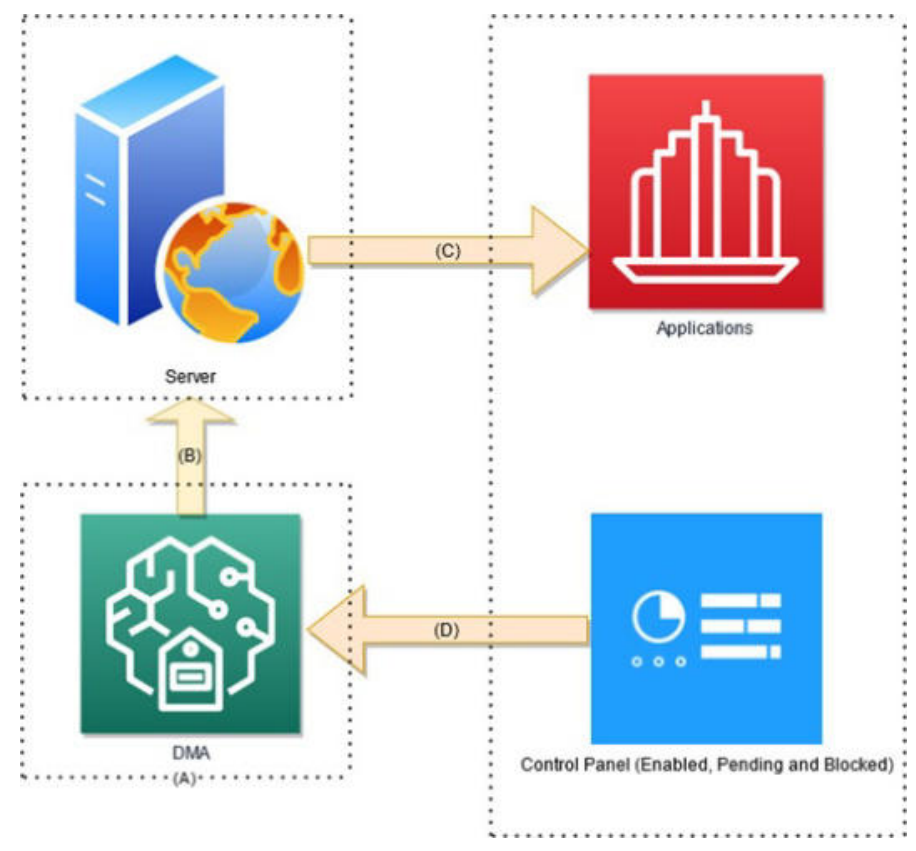

FIG. 1.1. The monitoring framework

in the scenario of real time otherwise to handle issues in the water supply systems; it may be late to handle the water supply system issues.

So, there is a requirement of effective mechanisms for the undesirable incident prevention and to operate and control these systems. To deal with unpredictable situations, the flexibility is required by the dynamic behaviour of water supply systems. The water management companies define and maintain the strict control to respect the operational and strategic policies. The various communication technologies and the other solutions are integrated by the wireless network infrastructure (IoT) for the people and object interaction. For the development of distinct applications, this is the remarkable technology for the smart cities. By focusing on engineering aspects and to reflect socioeconomic characteristics, agricultural water demand and supply is failed to analyze. For increase the supply, supply side is focussed by the agricultural water management. For the demand management, the patterns of internal water use are changes due to increase in water demand in the non-agricultural sector. To changes in internal and external conditions related to agricultural water, existing agricultural water supply has the limitations in the agricultural water utilization and management. The main focus is on increasing water supply by the management policies like upgrading infrastructure and installing additional facilities. The scarcity or opportunity is not reflected by costs of agricultural water and the management policies. By considering the realistic part of agricultural environment, agricultural water management is difficult to reform and improve. The design of a smart agricultural water management system is shown in Fig 1.2.

Numbers of nodes are consisted by the block-chain having distributed ledgers to allow the access and a ledger single edition is updated along with shared control maintenance. A distributed ledger contained in the Blockchain can record transactions between the nodes. The existence of third party is immediately avoided by the block-chain technology. The data is successfully released from the ledger by the blockchain technology progressing from centralized systems to a decentralized and network system is then distributed. It can also be used in business network. The Blockchain Elements are shown in Fig 1.3.

This paper is structured as follows. Many existing techniques are discussed in section 2. Research methodolgy is detailed in section 3. Discussion of experimental results obtained is presented in section 4 and section 5 concludes the paper. 


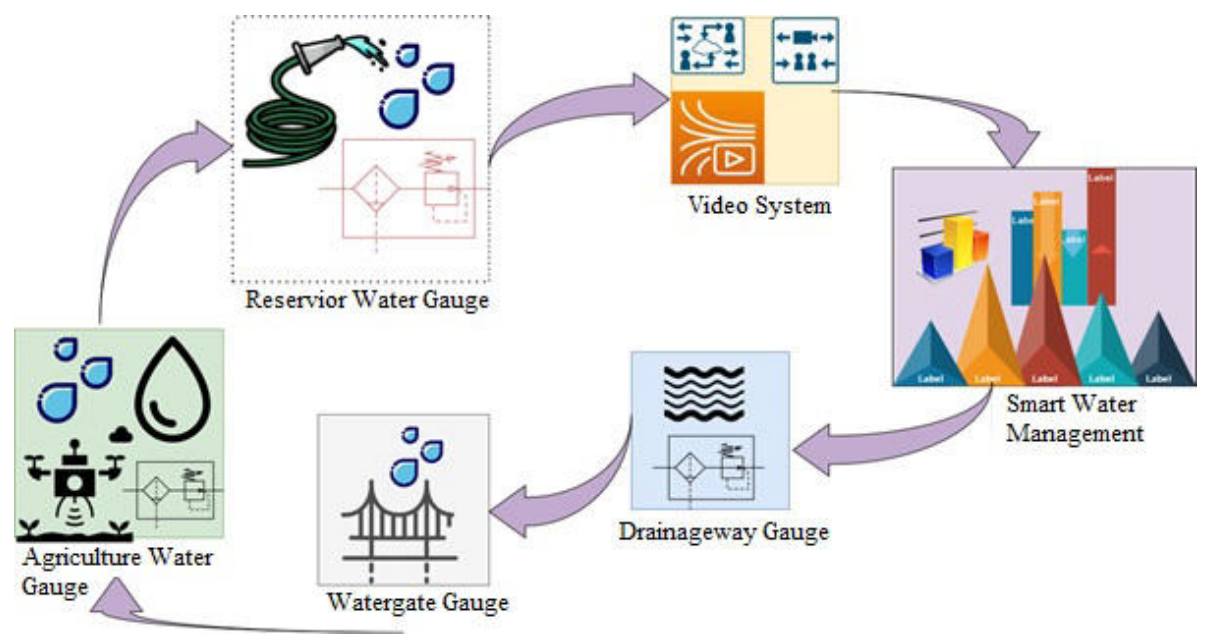

FIG. 1.2. Smart agriculture water management system

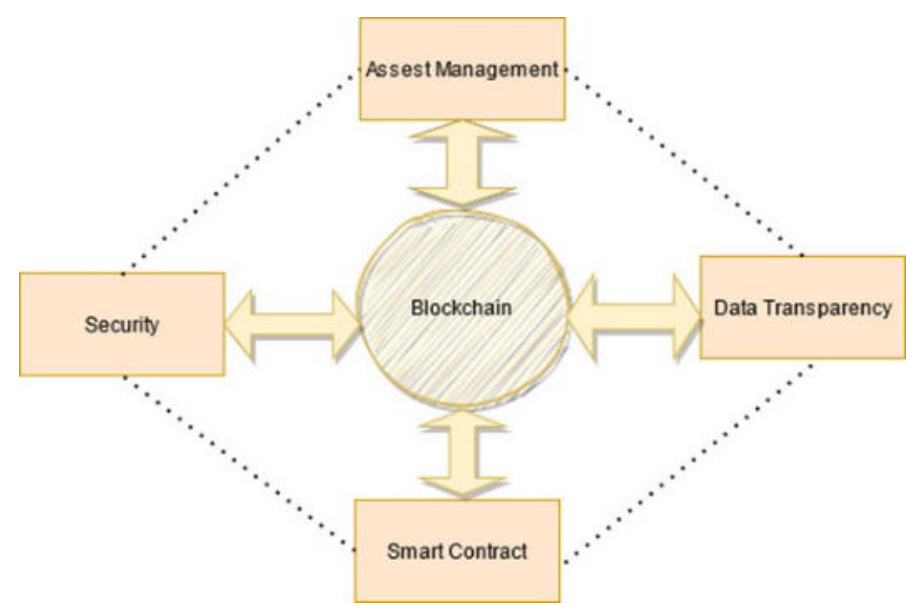

FIG. 1.3. Blockchain Elements

2. Literature Review. For the interaction between people and things/objects, the Internet of Things (IoT) is a wireless network infrastructure to integrate various communication technologies. For the development of distinct applications, distinct applications for the so-called smart cities are opened by the remarkable technology. For monitoring and controlling water supply systems, IoT is used in the context of water management. The high quality water demand is increased by the climate change with the increase in the world's population and for that new water strategies are created [18]. In this paper the author utilized the Internet of Things (IoT) technique and process the large amount of dataset which is produced by the sensors of IOT. The dynamic behaviour of water supply systems is too rigid to express by the traditional processes. A powerful, efficient, and flexible architecture is created by the IoT, CEP, and declarative processes for management of water supply system. The first solution is REFlex for supply systems combination. The REFlex Water architecture is detailed in this paper. The REFlex Water utilization is expanding to water supply system sectors.

The technicalization of agriculture progress and the informationization, IT technology of the agricultural ecosystem is increasing continuously [19]. There is great demand for agriculture water in rural areas so stable agricultural water supply is necessary. The smart agricultural water management system is designed and implemented for the effective management of agricultural water utilizing IoT based remote monitoring technology. For the management of agricultural water, a system is implemented through real-time data collection and 
analysis. The presented technique can efficiently manage the management of agricultural reservoirs and large river reservoirs.

A new topology of sensor nodes is presented by the author based on the highly efficient components. The water level, temperature and humidity are utilized [20]. The system main circuit board optimization is done by integrating layers and software optimization implementation. The IOT Block-chain is the emerging technique in which the distributed ledger is contained in the block-chain which enhances the security and data transparency [21]. In real time, blockchain is merged with the Internet of Thing. Author in this paper attempted to survey the core details of features of blockchain. The designed architecture is proposed in this paper for Smart Agriculture and ended up with some new architectural framework by merging the IOT and the blockChain. In this paper, authors' details how the blockchain technology can help to utilized the water more effectively in the network [22]. In the water management system with the water ultimate goal, the presented architecture serves as the basis for blockchain helps inbuilding transparency. To create a smart water management system is the main objective using blockchain technology. While contributing to environmental sustainability and for increasing crop yield, smart management of freshwater is utilized for the precision irrigation in agriculture [23]. For water management applications, the IoT is the natural thing even though the different technologies essential for making it work seamlessly. An IoT-based smart water management platform is developed by the SWAMP project for precision irrigation in agriculture. The SWAMP architecture, platform is presented by the author for IoT applications. Specially designed configurations of some components are required to provide adequate performance and utilizing less computational resources.

Water management affects the agriculture as a large amount of water is used [24-26]. To ensure the availability of water for food production and consumption, global warming is considered. The low-cost sensors are offered by the manufacturers for irrigation management and agriculture monitoring. For agriculture irrigation systems, the commercial sensors are very expensive for agriculture irrigation systems.

The advanced techniques can be applied in the development of these systems development and regarding smart irrigation systems is presented by the authors. Regarding water quantity and quality, soil characteristics and weather conditions, the different parameters are determined for irrigation systems monitoring. The most utilized nodes and wireless technologies are detailed by the author in this paper. The provenance of food can be tracked by the blockchain technology [28-31]. The applications of blockchain technology are examined by the author in food supply chains, agricultural insurance and smart farming. The challenges of recording transactions are discussed which are made by smallholder farmers and the ecosystem for utilizing the block-chain technology is created in the food sector [31-34]. For precision irrigation, The IoT-based systems are mostly theoretical and with the limited proof of concept experiences. They do not address the deployment of system for reliability facilitating and streamlining the deployment of new systems. The advanced features are provided by the water management and there is no need of the isolated initiatives connection to the existing architecture.

Contribution: A smart water management system based on the IOT and Block Based Chain is designed and implemented for the agriculture. It ensures the complete system is highly effective for the agriculture water management. The IoT sensor network technology is utilized with the remote monitoring for this purpose. By linking with 2D modelling, the control and management of the agriculture water were performed. Finally, a system is implemented for the agriculture water management through the real time data collection.

\section{Research Methodology.}

3.1. Integrated management system. In the agriculture sector, an efficient water management is very important and in this paper, we designed such a smart agricultural water management system. The IoT technology and remote monitoring technology is utilized to the existing water management infrastructure. For water resources management and water supply, this is the very efficient technology.

In the floods and droughts, there are natural changes in the recent years and in the rural area, disasters are according. To secure agricultural water and to cope with the damage of crops, a reservoir is installed which solves all these problems. During floods, there are damages by the river overflow and to prevent it flow to the reservoir is by passed to lower the level of the river. The sensor monitoring network system is essential for all this. The optimal supply of agricultural water is identified by the sensor monitoring for the water supply and management. For crop growth, the optimal amount of water is found for the excessive consumption of agricultural water supply. 


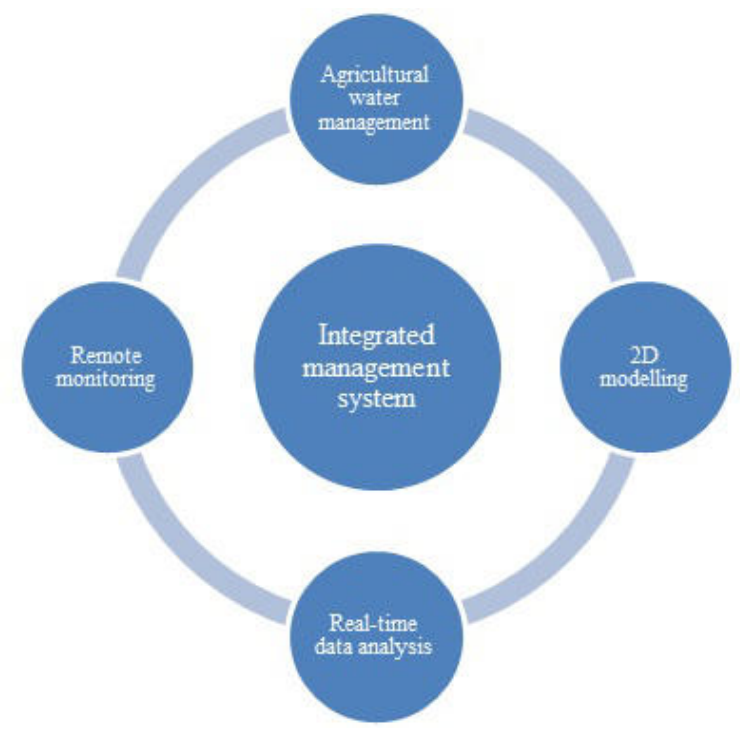

FIG. 3.1. Four modules of an integrated management system

The reservoir at all times is monitored by the water level sensor reservoir. If the rainwater supply is not smooth then the river water can be utilized for agriculture. The various problems in the exiting water management system are solved by the smart water management system and also an effective agricultural water system manages more efficiently. Four modules are finally utilized and integrated into an integrated management system such as agricultural water management, 2D modelling, real-time data analysis, and finally the remote monitoring as shown in Fig 3.1. The first module is responsible for the agricultural water management and the operation status of agricultural water related waterway is analyzed, and agricultural water related devices are also controlled. The structural safety of the development system is secured by the second module and the smart drainage system performance is analysed. The real - time data analysis is the third module for the designing of DB integrated system for remote monitoring. A smart drainage system and quality of water management function is finally developed by the remote monitoring module. The maintenance management system is finally developed and integrated with control systems and remote monitoring.

The agricultural water demand has the important characteristics as it requires the amount of agricultural water which is determined by the various factors like soil, climate and crops agriculture. As an important determinant of agricultural productivity stability and agricultural productivity, stable supply of agricultural water has been regarded.

The declarative notation is described and depicted in Fig 3.2. The sequence of activities is not defined here as it is declarative notation and all the activities are the rectangles. There is a chain response for the obligation of immediate execution and it is just one kind of rule. In this rule, the next activity to be executed is the activity at the end of the rule whenever the source activity is performed. The next activity is turning on all the pumps after reaching the minimum level. It will be turn on the next pump when the output flow. The set of interconnected hydraulic components are denoted by the water supply system for the water collection from the lakes and the water treatment procedures are applied for water distribution to the final consumers.

Following elements are included in water supply system:

1) Water source: Found in environment.

2) Water pumps: Set of equipments and installations for water collection from lakes.

3) Water transmissions: Raw water transportation to the water treatment facilities.

3.2. Implementation of the Proposed Technique. An innovative method is proposed in this paper to eliminate the water stress i.e., Blockchain Technology. Initially, water token is generated by the blockchain and then transaction of water is done as water shared among 10 households. The different transactions functions 


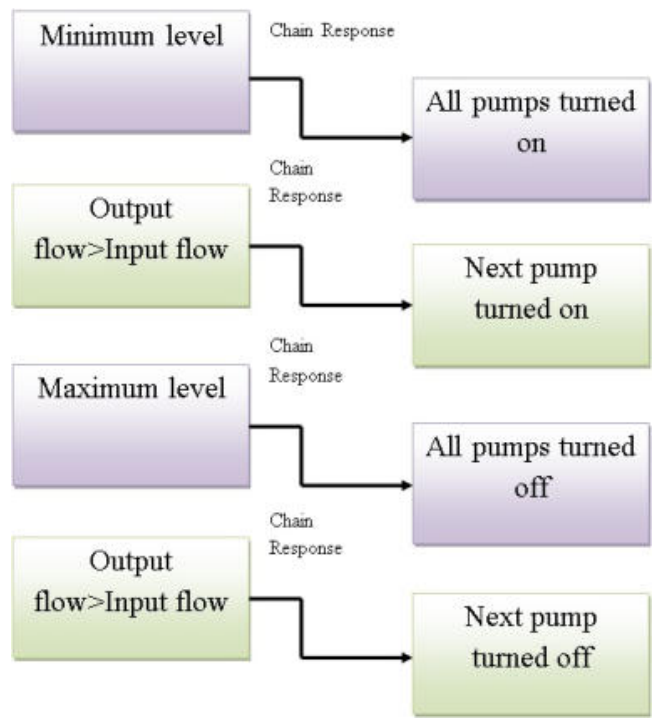

Fig. 3.2. Water Supply Process

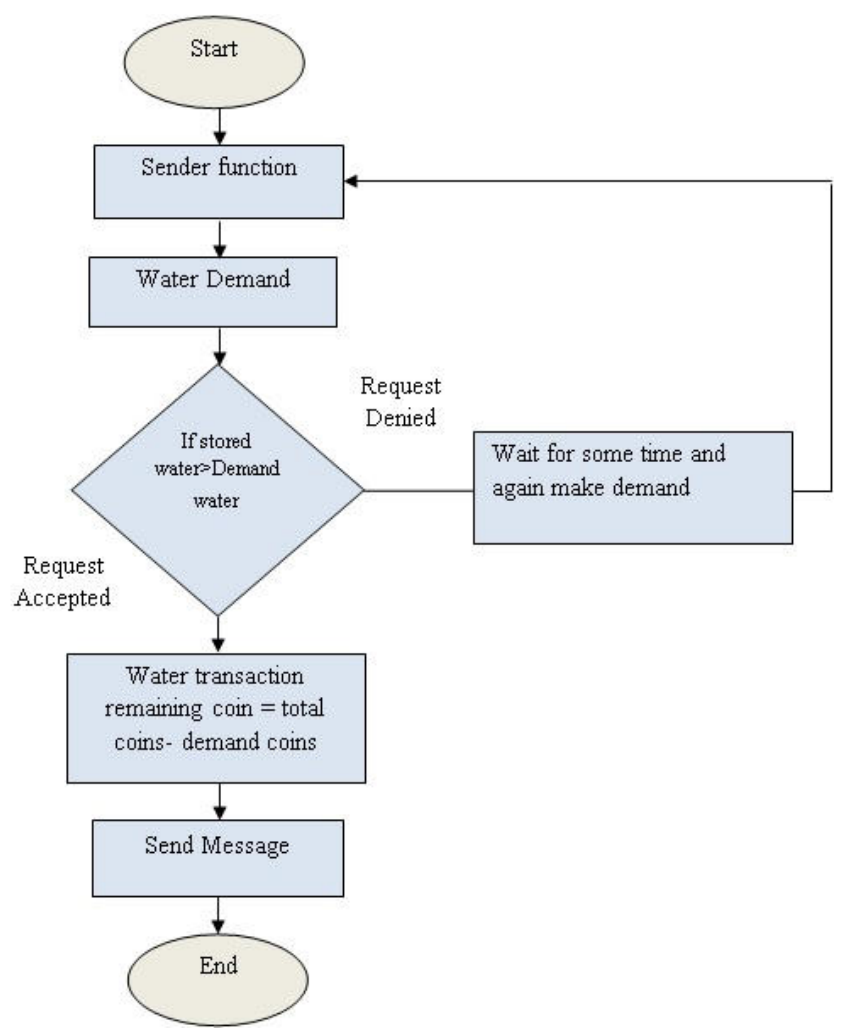

FIG. 3.3. Process of transaction in Sender's Side

are consisted in the smart contract as shown in Fig 3.3 and Fig 3.4. All transactions were written in solidity and run on Ethereum as platform. For water demand, the process of transactions is depicted in this Fig 3.3 which is occurring at sender's side. Any household can occur the demand and if it is accepted than it pass the transaction otherwise user have to wait for some time for the demand. The process of transaction occurring at 


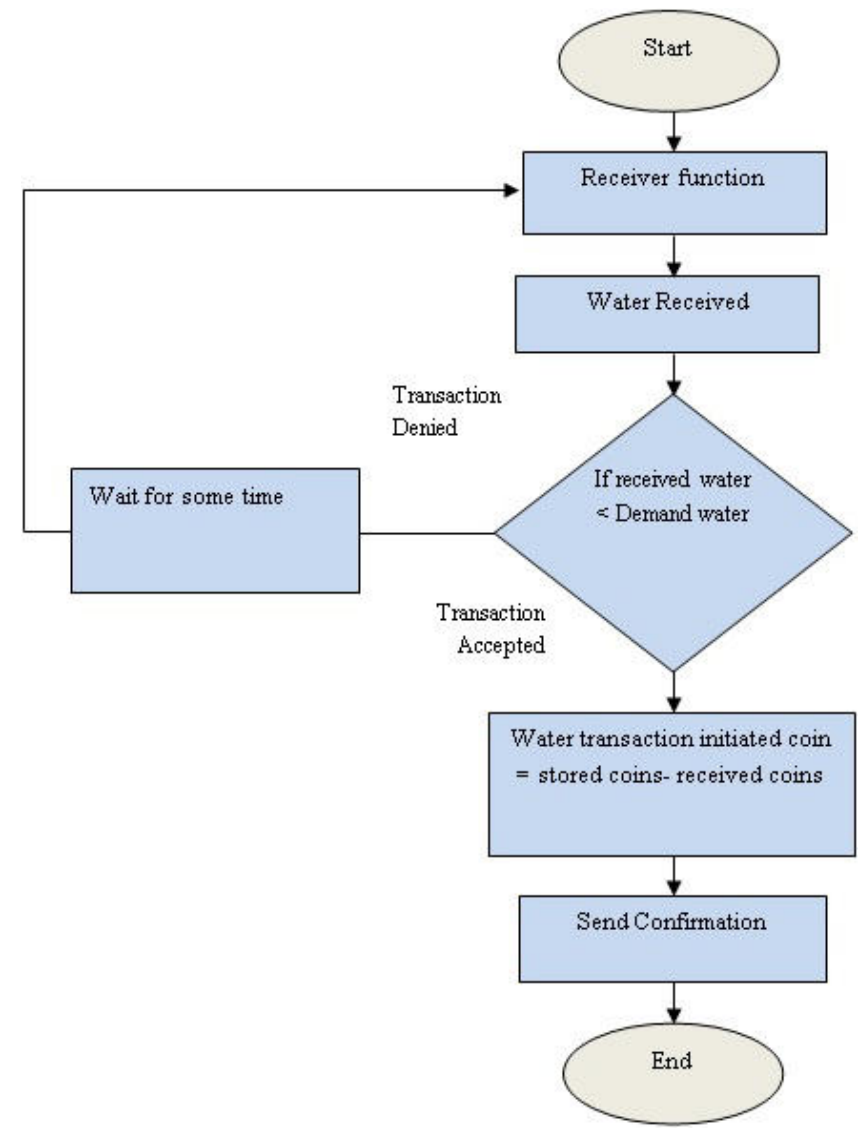

FIG. 3.4. Process of transaction in receiver's Side

receiver side is depicted in Fig 3.4. The acceptance of water demand request is shown in the figure. If demand coin equals to receive coins, transaction pass when water received from any household otherwise user have to wait for another time to make another demand.

\section{Results and Discussion.}

4.1. Water Monitoring Interface . In this section, a solution for intelligent water management and the water architecture is evaluated and analyse the performance. The event processing and the declarative processes are utilized for this purpose. The practical use of water management system which is installed in the city is evaluated and demonstrated in this section. The declarative business processes in the context of water distribution systems having varying merits which are also discussed here. The imperative process modelling language is utilized for the traditional workflow management systems which are helpful for the standardized and modelling static systems. However, an adequate response is not provided when the chaotic and dynamic processes are utilized.

A team of highly skilled and experienced professionals are required by the system for the water management. The unexpected situations are adapted by the professionals which accur in this scenario. Over water management policies, flexibility, and maintain control are offered by the declarative processes.

Table 4.1 represents the data that updates the water monitoring interface and it is also represented graphically. Flow of water through pump 1 is shown in Fig 4.1 and the water flow from the pump 2 is presented in Fig 4.2.

The raw water sources, pump, pipes, stations, tanks and all other components are in the same layer (Physical) which also contains water meters, IOT devices to measure the pressure and volume in pipes and 
TABLE 4.1

Data that updates the water monitoring interface

\begin{tabular}{||l|l|l|l||}
\hline Time (Hours) & Pump 1 Flow (lps) & Pump 2 Flow (lps) & Tank Level $(\mathrm{m})$ \\
\hline \hline 00.00 & 17.98 & 10.00 & 180.00 \\
\hline 01.00 & 21.07 & 0.00 & 180.00 \\
\hline 02.00 & 19.87 & 0.00 & 180.00 \\
\hline 03.00 & 13.78 & 0.00 & 180.03 \\
\hline 04.00 & 23.87 & 0.00 & 180.08 \\
\hline 05.00 & 18.94 & 0.00 & 180.00 \\
\hline 06.00 & 21.45 & 10.64 & 180.00 \\
\hline 07.00 & 13.87 & -3.12 & 180.05 \\
\hline 08.00 & 22.43 & 4.98 & 180.09 \\
\hline 09.00 & 8.67 & 17.32 & 180.02 \\
\hline 10.00 & 14.67 & 23.78 & 180.00 \\
\hline
\end{tabular}

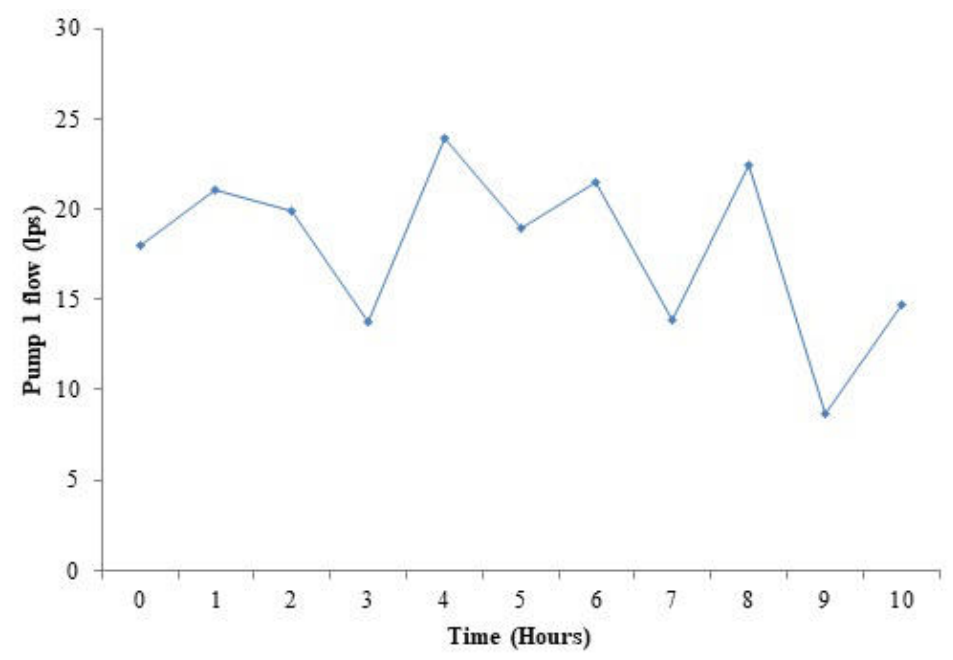

FIG. 4.1. Flow of water through pump 1

water tank respectively. Network sensors and actuators are connected to a gateway. The middleware layer provides the storage, analysis, processing, and orchestrating services and the communication between the two layers and also in IOT infrastructure of sensors and actuators.

To test the performance of the IOT devices, the benchmark tool CoAPBench is utilized. The confirmation requests are sending by the system and then waiting for the response before the next request. The IOT device is connected with the blockchain and it receive the request, fetches the information and response is returned to the IOT devices.

To check whether the plants are irrigated or not, sensed data is transmitted to server in four, five times in a day and the threshold values of temperature, humidity and moisture are checked with these values for the comparison. The user got the notification when the plants watering condition is fulfilled. Experiments are done and the results are obtained which are tabulated in Table 4.2. For more clear vision, it is also shown graphically in Fig 4.3.

Maximum of security is ensured by the water management system based on the blockchain in water supply system. Here some of the security issues are listed:

i. IoT devices are checked regularly and carried out the outputs.

ii. Proper paring of Public/ private key. 


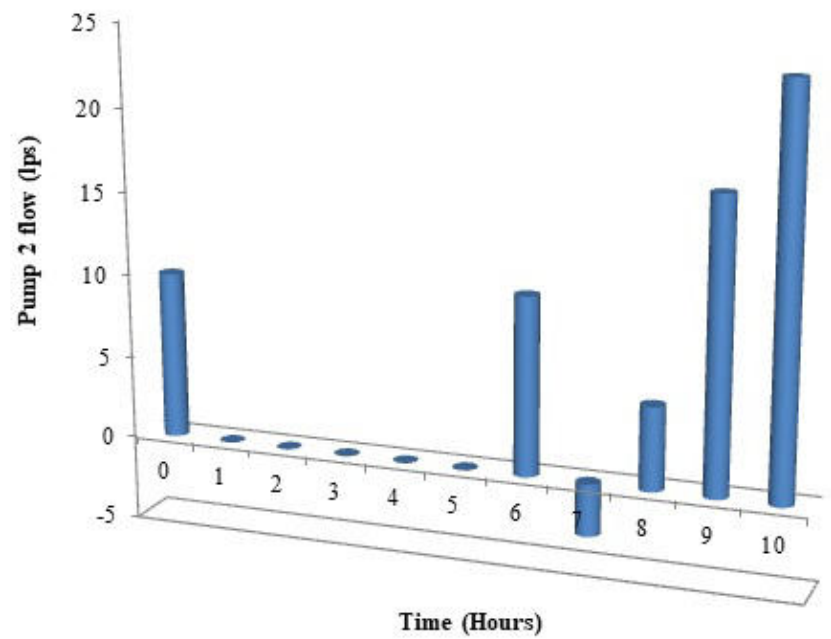

FIG. 4.2. Flow of water through pump 2

TABLE 4.2

Water management results for 6 experiments

\begin{tabular}{||l|l|l|l|l||}
\hline Sr. No. & Moisture (voltage) & Humidity (Percentage) & Temperature $\left({ }^{\circ} \mathrm{C}\right)$ & Time (Minutes) \\
\hline \hline 1 & High & 7.34 & 2.32 & 2.30 \\
\hline 2 & High & 5.21 & 2.76 & 1.55 \\
\hline 3 & High & 3.67 & 1.89 & 4.25 \\
\hline 4 & High & 12.32 & 7.65 & 8.40 \\
\hline 5 & High & 15.54 & 9.45 & 2.10 \\
\hline 6 & High & 12 & 5.56 & 1.23 \\
\hline
\end{tabular}

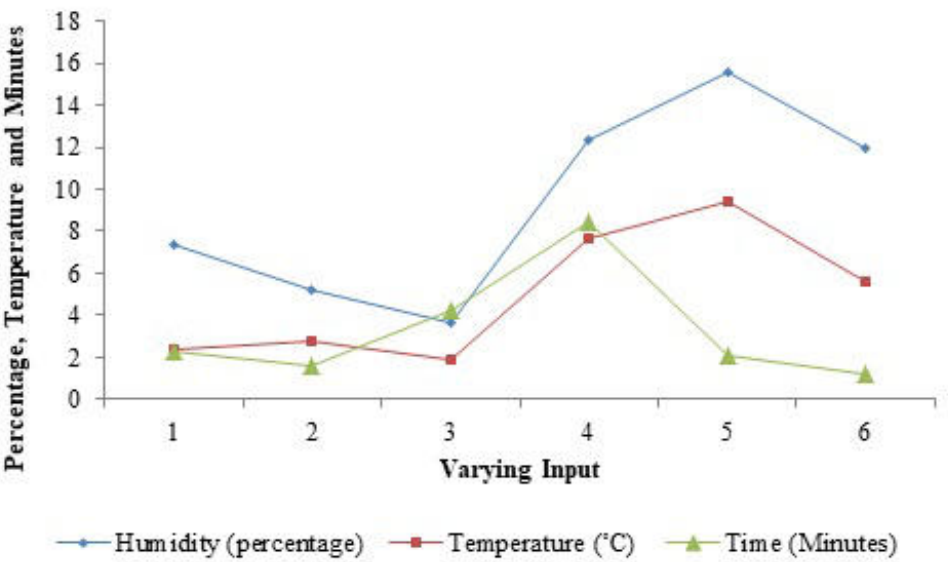

FIG. 4.3. Water management results in terms of humidity, temperature and time

iii. Digital signature security is ensured by the system.

iv. Regularly inspection of consumer feedback. 
TABLE 4.3

Comparison of the proposed technique with existing technique

\begin{tabular}{||l|l|l|l|l||}
\hline $\begin{array}{l}\text { Sr. } \\
\text { No. }\end{array}$ & $\begin{array}{l}\text { Existing Technique } \\
\text { [19] Humidity (Per- } \\
\text { centage) }\end{array}$ & $\begin{array}{l}\text { Existing Technique } \\
{[19] \text { Time (Minutes) }}\end{array}$ & $\begin{array}{l}\text { Proposed Technique } \\
\text { Humidity (Percent- } \\
\text { age) }\end{array}$ & $\begin{array}{l}\text { Proposed Technique } \\
\text { Time (Minutes) }\end{array}$ \\
\hline \hline 1 & 8.78 & 3.20 & 7.34 & 2.30 \\
\hline 2 & 5.89 & 2.54 & 5.21 & 1.55 \\
\hline 3 & 4.56 & 5.24 & 3.67 & 4.25 \\
\hline 4 & 13.78 & 9.35 & 12.32 & 8.40 \\
\hline 5 & 16.43 & 3.54 & 15.54 & 2.10 \\
\hline 6 & 13.56 & 3.65 & 12 & 1.23 \\
\hline
\end{tabular}

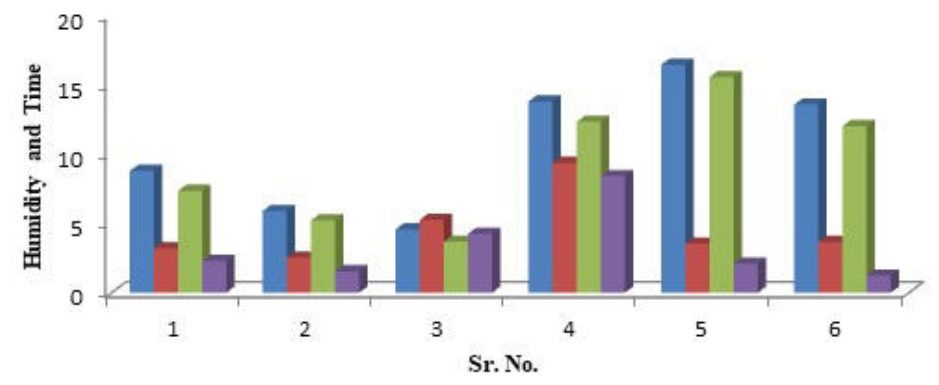

Existing Technique [19] Humidity (Percentage) $\equiv$ Existing Technique [19] Time (Minutes)

= Proposed Technique Humidity (Percentage) $\quad$ - Proposed Technique Time (Minutes)

FIG. 4.4. Comparison of the proposed technique with existing technique

4.2. Comparison of the Proposed Technique with the Existing Technique. The comparison of the results obtained by the proposed technique is done with the existing technique for the validation purpose. This comparison shows the improvement of the proposed technique. The threshold values of temperature and time are checked and compared with the state-of-the art technique as tabulated in Table 4.3.

For better visualization and analysis, the comparison values in terms of humidity and time are also represented graphically as shown in Fig 4.4. It is clear from the figure that the humidity and time is less by the proposed technique.

The percentage improvement of the proposed technique is also calculated and the improvement of the proposed technique is shown in terms of the humidity (percentage) and time (minutes). The percentage improvement of the proposed technique is tabulated in Table 4.4.

For proper validation and analysis purpose, the visual graphical represented is presented in Fig 4.5. The percentage improvement over existing technique is shown graphically in terms of humidity and time.

It is clear from the figure that the proposed technique is better in terms of humidity of time. On an average the presented technique is $14.5 \%$ better than the existing technique in terms of humidity and the improvement of $67.5 \%$ is shown over the existing technique in terms of time.

5. Conclusion. The block-chain technology and IoT based technique with its features are detailed briefly. In the context of water systems management, the combination of these technologies is a powerful tool. It is very efficient and cost effective technique to control and monitor the real time aspects of water distribution. IOT based smart water management system is designed in this paper for the agriculture which ensures the effectiveness of the agriculture water management. The remote monitoring with the IOT is used for this 
TABLE 4.4

The proposed technique improvement over existing technique

\begin{tabular}{||l|l|l||}
\hline Sr. No. & $\begin{array}{l}\text { Percentage improvement In terms of Humidity } \\
\text { (Percentage) }\end{array}$ & $\begin{array}{l}\text { Percentage improvement In terms of Time } \\
\text { (Minutes) }\end{array}$ \\
\hline \hline 1 & 19.62 & 39.13 \\
\hline 2 & 13.05 & 63.87 \\
\hline 3 & 24.25 & 23.29 \\
\hline 4 & 11.85 & 11.31 \\
\hline 5 & 5.73 & 68.57 \\
\hline 6 & 13.00 & 196.75 \\
\hline
\end{tabular}

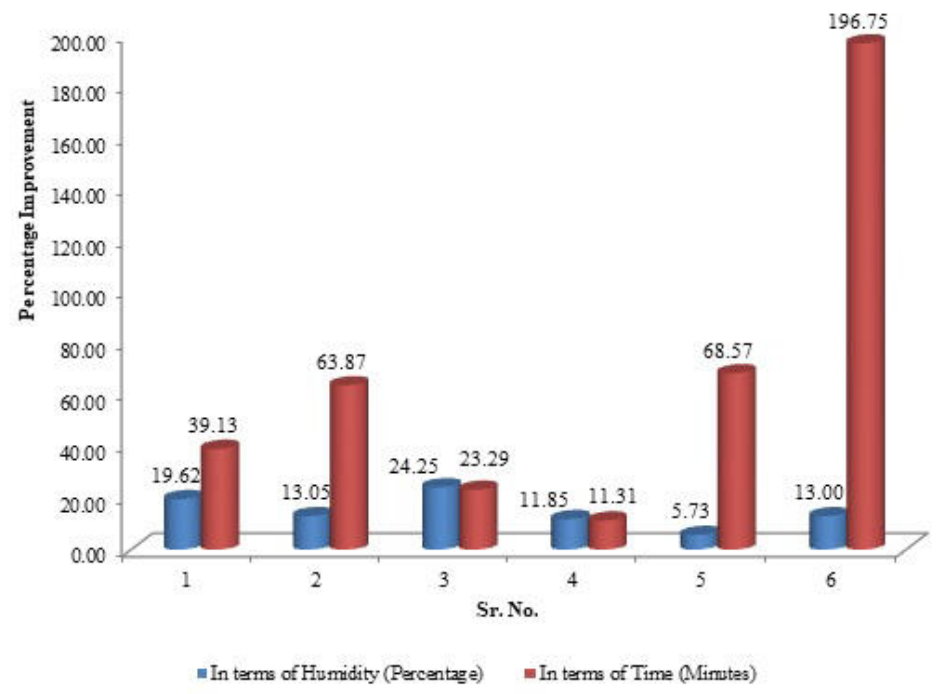

FIG. 4.5. Percentage improvement of the proposed technique

purpose. By linking with 2D modelling, the control and management of the agriculture water were performed. Finally, a system is implemented for the agriculture water management through the real time data collection. The obtained result shows the data that updates the water monitoring interface with the varying number of hours. The IoT technology and remote monitoring technology is utilized to the existing water management infrastructure. For water resources management and water supply, this is the very efficient technology.In future, IoT , blockchain and neural network based water management technique can be designed for the effective results.

\section{REFERENCES}

[1] Novo, O. , Blockchain meets IoT: An architecture for scalable access management in IoT, IEEE Internet of Things Journal, $5(2), 1184-1195,2018$.

[2] Nguyen, G. T. And Kim, K. , A Survey about Consensus Algorithms Used in Blockchain, Journal of Information processing systems, 14(1), 2018.

[3] Zheng, Z., Xie, S., Dai, H. N., Chen, X. And Wang, H. , Blockchain challenges and opportunities: A survey, International Journal of Web and Grid Services, 14(4), 352-375, 2018.

[4] Habib, K., Torjusen, A. And Leister, W , Security analysis of a patient monitoring system for the Internet of Things in eHealth, In The Seventh International Conference on eHealth, Telemedicine, and Social Medicine (eTELEMED), 2015.

[5] Zheng, Z., Xie, S., Dai, H., Chen, X. And Wang, H. , An overview of blockchain technology: Architecture, consensus, and future trends, In 2017 IEEE international congress on big data (BigData congress) (pp. 557-564). IEEE, 2017.

[6] Cammert, M., Heinz, C., Krämer, J., and Riemenschneider, T. , U.S. Patent No. 10,255,238. Washington, DC: U.S. Patent and Trademark Office.,2019. 
[7] Bijl, D. L., Bogant, P. W., Kram, T., De Vries, B. J., And van Vuuren, D. P. , Long-term water demand for electricity, industry and households, Environmental Science and Policy, 55, 75-86, 2016.

[8] Mouratiadou, I., Biewald, A., Pehl, M., Bonsch, M., Baumstark, L., Klein, D. And Kriegler, E. , The impact of climate change mitigation on water demand for energy and food: An integrated analysis based on the Shared Socioeconomic Pathways, Environmental Science and Policy, 64, 48-58, 2016.

[9] Davis, J. And Pearce, D. , TThe non-agricultural rural sector in Central and Eastern Europe, World Bank Technical Paper, $111-130,2001$.

[10] UnNi, J. , Non-agricultural employment and poverty in rural India: A review of evidence, Economic and Political Weekly, A36-A44., 1998.

[11] Davis, J., And PeARCE, D. , The non-agricultural rural sector in Central and Eastern Europe, World Bank Technical Paper, $111-130,2001$

[12] Basant, R., And Kumar, B. L. , Rural non-agricultural activities in India: A review of available evidence, Social Scientist, 13-71, 1989.

[13] Dev, S. M. , Non-agricultural employment in rural india: Evidence at a disaggregate level, Economic and Political Weekly, $1526-1536,1990$.

[14] XiE, H., AND LU, H. , Impact of land fragmentation and non-agricultural labor supply on circulation of agricultural land management rights, Land Use Policy, 68, 355-364, 2017.

[15] Kuo, T. T., Kim, H. E.And Ohno-Machado, L. , Blockchain distributed ledger technologies for biomedical and health care applications, Journal of the American Medical Informatics Association, 24(6), 1211-1220,2017.

[16] Beck, R., Avital, M., Rossi, M. And Thatcher, J. B. , Blockchain technology in business and information systems research., 2017.

[17] Gonçalves, R., JM Soares, J., And MF Lima, R. , An IoT-Based Framework for Smart Water Supply Systems Management, Future Internet, 12(7), 114,2020.

[18] Rajakumar, G., Sankari, M. S., Shunmugapriya, D. And Maheswari, S. U. , IoT based smart agricultural monitoring system, Asian J. Appl. Sci. Technol, 2, 474-480, 2018.

[19] Khoa, T. A., Man, M. M., Nguyen, T. Y., Nguyen, V., and Nam, N. H. , Smart Agriculture Using Iot Multi-Sensors: A Novel Watering Management System, Journal of Sensor and Actuator Networks, 8(3), 45, 2019.

[20] Devi, M. S., Suguna, R., Joshi, A. S. And Bagate, R. A, Design of IoT blockchain based smart agriculture for enlightening safety and security, In International Conference on Emerging Technologies in Computer Engineering (pp. 7-19). Springer, Singapor, 2019.

[21] Kumar, M. V., And Iyengar, N. C. S. , A framework for Blockchain technology in rice supply chain management, Adv. Sci. Technol. Lett, 146, 125-130, 2017.

[22] Kamienski, C., Soininen, J. P., Taumberger, M., Dantas, R., Toscano, A., Salmon Cinotti, T., ... and Torre Neto, A. , Smart water management platform: Iot-based precision irrigation for agriculture, Sensors, $19(2), 276,2019$.

[23] García, L., Parra, L., Jimenez, J. M., Lloret, J. and Lorenz, P. , IoT-Based Smart Irrigation Systems: An Overview on the Recent Trends on Sensors and IoT Systems for Irrigation in Precision Agriculture, Sensors, $20(4), 1042,2020$.

[24] Xiong, H., Dalhaus, T., Wang, P. And Huang, J. , Blockchain Technology for Agriculture: Applications and Rationale, frontiers in Blockchain, 3, 7, 2020.

[25] Sharma, A., And Kumar, R. , A framework for pre-computated multi-constrained quickest qos path algorithm, Journal of Telecommunication, Electronic and Computer Engineering (JTEC), 9(3-6), 73-77, 2017.

[26] Nesarani, A., Ramar, R., And Pandian, S. , An efficient approach for rice prediction from authenticated Block chain node using machine learning technique, Environmental Technology and Innovation, 20, 101064, 2020.

[27] Sharma, A., Ansari, M. D., And Kumar, R. , A comparative study of edge detectors in digital image processing, In 2017 4th International Conference on Signal Processing, Computing and Control (ISPCC) (pp. 246-250). IEEE, 2017.

[28] Gusmeroli, S., Piccione, S., And Rotondi, D. , IoT access control issues: a capability based approach, . In 2012 Sixth International Conference on Innovative Mobile and Internet Services in Ubiquitous Computing (pp. 787-792). IEEE, 2012 .

[29] Negi, S., Sharma, A., And Kumar, K. , Analysis of Blast Load on Structure using SAP2000, 2019.

[30] Le, D. P., Meng, H., Su, L., Yeo, S. L., And Thing, V. , Biff: A blockchain-based iot forensics framework with identity privacy, In TENCON 2018-2018 IEEE Region 10 Conference (pp. 2372-2377). IEEE, 2019.

[31] Sharma, A., And Kumar, R., Computation of the reliable and quickest data path for healthcare services by using service-level agreements and energy constraints, Arabian Journal for Science and Engineering, 44(11), 9087-9104, 2019.

[32] Daza, V., Di Pietro, R., Klimek, I. And Signorini, M. , CONNECT: CONtextual NamE disCovery for blockchain-based services in the IoT, . In 2017 IEEE International conference on communications (ICC) (pp. 1-6). IEEE, 2017.

[33] Kumar, D., Sharma, A., Kumar, R. And Sharma, N. , Restoration of the Network for Next Generation (5G) Optical Communication Network, In 2019 International Conference on Signal Processing and Communication (ICSC) (pp. 6468). IEEE, 2019.

[34] Pyoung, C. K.And BAEK, S. J. , Blockchain of Finite-Lifetime Blocks With Applications to Edge-Based IoT, IEEE Internet of Things Journal, 7(3), 2102-2116, 2019.

Edited by: Pradeep Kumar Singh

Received: Apr 25, 2021

Accepted: Sep 20, 2021 